Available online at: http://ejournal-balitbang.kkp.go.id/index.php/ifrj
e-mail:ifrj.puslitbangkan@ gmail.com
INDONESIANFISHERIESRESEARCHJOURNAL
Volume 23 Nomor 2 December 2017
e-ISSN: 2502-6569

\title{
TECHNICAL EFICIENCY OF FISH AGGREGATING DEVICES ASSOCIATED WITH TUNA FISHERY IN KENDARI FISHING PORT - INDONESIA
}

\author{
Moh. Natsir*1, Agustinus Anung Widodo' ${ }^{1}$, Wudianto ${ }^{1}$ and Sveinn Agnarsson ${ }^{2}$ \\ ${ }^{1}$ Center for Fisheries Research, Gedung BALITBANGKP II, Jalan Pasir Putih Ancol Jakarta Utara-14430, Indonesian \\ ${ }^{2}$ School of Business, University of Iceland, 101 Reykjavik, Iceland \\ Received; April 10-2017 Received in revised from January 26-2018; Accepted January 30-2018
}

\begin{abstract}
Kendari fishing port is one of the biggest tuna fisheries landing in Indonesia. It yearly average tuna production was more than 20 thousand tons. The tuna fishing fleet in Kendari use FAD (Fish Aggregating Devices) as an auxiliary fishing gear. FAD management is major issues in Indonesian tuna fisheries. extensive investment on FAD has led to increase of the juvenile and by catch and also social problem because of the competition. Technical efficiency analysis was done during this study, 2015 catch and logistic data from Kendari fishing port was run using stochastic frontier to obtain the model. Mean value technical efficiency was 0.534 . Purse seine the highest mean value compared to other fishing gear. All the variables input show positive relationship to the catch except the days at sea variables, this is a signal that the increasing number of FAD has made the fisherman spend more time at sea it will decrease the technical efficiency. The results support the need of FAD regulation done by the government of Indonesia. Regulation will keep the number of FAD at optimum level and increase the technical effieciency so the fisheries keep gaining the optimum benefit from the resources.
\end{abstract}

Keywords: Purse seine; Pole and line; Stochastic frontier; Fish aggregating device; Tuna

\section{INTRODUCTION}

Located in South East Sulawesi, Kendari ocean fishing port is one of the six biggest fishing ports in Indonesia together with Jakarta and Cilacap in Java, Bitung in Sulawesi, Belawan and Bungus in Sumatera. The average total fish landing in Kendari fishing port for the last 5 years, from 2010-2014, amounted to 20 thousand tons, where of average FAD associated with tuna fishing fleets landing was 19.5 thousand tons or more than $95 \%$ of total catches. According to Directorate General of Capture Fisheries (2013), the port is an important fishing centre for the more than 77.000 fishers in South East Sulawesi.

The Kendari tuna fishing fleet is dominated by three types of fishing gears; purse seine, pole and line, and troll line. In all cases, FADs are used as an auxiliary fishing gear since the 1980's. Vessels range in size from less than 5 GRT to 200 GRT, dominated by small scale fishery under the 30 GRT size, and trips lengths vary from 1 day fishing to 3 weeks (21 days). In some fishing regions, transhipment to collecting vessels are common and collaboration of smallholder's partnership scheme (i.e. mitra kolaborasi) is also frequent. FADs are often provided to fishers through Provincial and Regency government assistance programs, but there are also many that are privately installed and privately owned

Stochastic frontier analysis (SFA) is a method used to estimate the efficiency of individual production units. The theory was introduced simultaneously by Meeusen \& van den Broeck (1977) and Aigner et al. (1977), but since then more complex models have been developed. The technical efficiency (TE) of a firm or another production unit is defined as the ratio of observed output to maximum and feasible output. In cases where the observed TE of firm $i$ takes on a value of unit, the $i$-th firm is said to be fully technical efficient, while $T E_{i}<1$ indicates the firm is experiencing a shortfall of the observed output from maximum feasible output. In the former case, the firm may be said to lie on the production frontier, while in the second case it would find itself below the frontier. In SFA, the random component of an ordinary regression is split into a one-sided stochastic component, that captures the inefficiency, and a pure white noise component. The stochastic component describes random shocks that may affect the production process but are not directly attributable to the producer or the underlying technology. Typically, these shocks could be brought about through changes in weather, economic adversities or plain luck. 
Stochastic frontier analysis has frequently been applied to the in fisheries sector, both aquaculture and capture fisheries. Early studies on efficiency in the harvesting sector include Kirkley et al. (1995, 1998), Coglan et al. (1999), Sharma \& Leung (1999), Squires \& Kirkley (1999), Pascoe et al. (2001) and Pascoe \& Coglan (2000). The model developed by Battese \& Coelli (1995) has been employed by Fousekis \& Klonaris (2003) to investigate the technical efficiency of the trammel net fishery in Greece while Ghee-Thean et al. (2012) use stochastic frontier analysis to analyze how technology and other determinants have affected the fishing efficiency of a trawl fishery in Malaysia.

Stochastic frontier analysis study for purse seine fishery in Java Sea Indonesia has done by Jeon et al. (2006), it discusses stochastic production frontier in developing country fishery and the effect of seasonality, vessel ownership, and captain schooling experience, location of the landing and the dimension of the vessel on technical efficiency. Application of this model to Indonesian fisheries with FAD is still not available yet. This study was intended to measure the technical efficiency in FAD associated with tuna fisheries based in Kendari fishing port.

\section{MATERIALS AND METHODS}

Data for this study were collected in Kendari fishing port during year 2015 period, daily and individual vessel landing data collected by Kendari fishing port authority. Three data categories were collected, first data category was the vessel logistic information consist of number of crew, fuel, waters and ice, second data category was catch information consist of number of catch, additional information about fishing ground (information about the fishing ground location), number day at sea and name of the captain also recorded during the catch landing monitoring. Third data category was the vessel information recorded on the vessel registration i.e fishing gear, vessel dimension (length,width and depth), GT, owner name and registration number. Variables description and the measurement unit are shown in Table 1.

Collected data were tabulated and verified, only complete data set (logistic, catch and vessel information) will be used for the technical efficiency analysis. After tabulation and verification process total 2598 data set consist of 2107 purse seine fleet data, 26 pole and line data set, and 466 hand line and troll line data set were selected to be analyzed.

The model was estimated using maximum likelihood. For this purpose the frontier $R$ package developed by Coelli \& Henningsen (2013) was employed. Use was also made of the plm R package developed by Croissant \& Millo (2008). In applied microeconomics, efficiency may be calculated using either parametric or non-parametric methods. This study used the former approach and calculate technical efficiency (TE) using a model developed Battesse \& Coelli (1995).

Consider the stochastic production function for panel data,

$Y_{i t}=\exp \left(x_{i t} \beta+V_{i t}-U_{i t}\right)$

or taking logs

$\operatorname{In}\left(Y_{i t}\right)=x_{i t} \beta+V_{i t}-U_{i t}$

Here, $Y_{i t}$ denotes the production of firm / at time $t$ $x_{i t}$ is a $(1 \mathrm{x} \mathrm{k})$ vector values of inputs and other explanatory variables, while $\mathrm{V}_{\mathrm{it}}$ is a random error term and $U_{i t}$ are non-negative random variables, associated with technical inefficiency of production.

The technical inefficiency effect, in the stochastic frontier model is specified as, where $z_{i t}$ is a vector of explanatory variables associated with technical inefficiency, and $\delta$ are unknown coefficients. The random variable, $W_{i t} \delta$ is defined by the truncation of the normal distribution with zero mean and variance, $\sigma^{2}$, such that the point of truncation is-- $z_{i t} \delta$ i.e., $W_{i t} \delta$ $>-\mathrm{z}_{\mathrm{it}} \delta$. These assumptions are consistent with $\mathrm{U}_{\text {it }}$ being a non-negative truncation of the $N\left(\mathrm{z}_{\mathrm{it}} \delta \dot{O}^{2}\right)$ distribution.

The method of maximum likelihood is used to simultaneously estimate the parameters of the stochastic frontier and the model for the technical inefficiency effects. The technical efficiency of production for the $i$-th firm at the $t$-th observation may then be defined by

$\mathrm{TE}_{\mathrm{it}}=\exp \left(-\mathrm{U}_{\mathrm{it}}\right)=\exp \left(\delta_{0}-z_{i t} \delta-W_{i t}\right)$

Following Battese \& Coelli (1995), the model used for estimating the stochastic production frontier is given by:

$$
\begin{aligned}
& \ln \text { Cacth }_{\mathrm{i}}=\beta_{0}+\beta_{1} \operatorname{In}(\text { Dim })+\beta_{2} \ln (\text { Crew })_{i}+ \\
& \beta_{3} \ln (\text { DAS })_{i}+\beta_{4} \ln (\text { Ice })_{i}+\beta_{5} \ln (\text { Water })_{i}+V_{i}-U_{i}
\end{aligned}
$$

where the technical inefficiency effects are defined as a function of dummy variables: 
$U_{i}=\delta_{0}+\delta_{1}$ DumCap $2+\delta_{2}$ DumCap $3+$

$\delta_{3}$ DumCap $4+\delta_{4}$ DumCap $4 B+\delta_{5}$ DumfFG $3+$

$\delta_{6}$ DSoff $+\delta_{7}$ DSpeak $+W_{i}$

Here, the $\beta$ 's and $\delta$ 's are parameters to be estimated, while $V_{i}$ and $W_{i}$ are well-behave random error terms and $i$ indicates individual vessels.
Stochastic frontier model for the FAD associated tuna fisheries in Kendari was done using data for the year 2015. This includes observations on catches per trip, as well as information on vessel size, number of crew, days at sea, the amount of ice and water used on each trip, as well as information on the captain, fishing ground and gear used. Total 2598 data from 2015 landing monitoring being used during the technical efficiency analysis, Summary statistics are shown in Table 1.

Table 1. Summary statistics for variables included in stochastic production frontier and technical efficiency models for mixed FAD Associated tuna fisheries (Purse Seine, Pole and Line, Hand and Troll Line)

\begin{tabular}{|c|c|c|c|c|c|c|}
\hline \multirow[b]{2}{*}{ Variables } & \multirow[b]{2}{*}{ Description } & \multirow[b]{2}{*}{ Measurement } & \multicolumn{4}{|c|}{ summary statistics } \\
\hline & & & Mean & $\begin{array}{l}\text { Stad } \\
\text { dev }\end{array}$ & Min & Max \\
\hline \multicolumn{7}{|l|}{$n=2598$} \\
\hline \multicolumn{7}{|c|}{ Output and input variables } \\
\hline Y(Catch) & Catches & $\mathrm{Kg}$ & $3,632.8$ & $2,640.6$ & 204 & 23,256 \\
\hline Crew & Number of crew & person & 14.3 & 5.2 & 3.0 & 30.0 \\
\hline Dim & $\begin{array}{l}\text { Size of vessel (length } x \\
\text { wide } x \text { depth) }\end{array}$ & $\mathrm{m}^{3}$ & 83.31 & 63.13 & 7.7 & 270.46 \\
\hline DAS & Day spent at sea & days & 5.4 & 2.7 & 1.0 & 45.0 \\
\hline Ice & Quantity of ice & ice block & 84.5 & 49.6 & 11.0 & 900.0 \\
\hline Water & Quantity of water & 1000 litres & 1.3 & 0.7 & 0.1 & 7.5 \\
\hline Fuel & Quantity of fuel & Litre & 674.0 & 427.3 & 30.0 & 15,000 \\
\hline \multicolumn{7}{|c|}{ Vessel specific variables } \\
\hline DumCap1 & 2 trips or fewer & Dummy & 0.19 & 0.39 & 0 & 1 \\
\hline DumCap2 & 2 - 6 trips a year & Dummy & 0.25 & 0.43 & 0 & 1 \\
\hline DumCap3 & $6-12$ trips a year & Dummy & 0.27 & 0.44 & 0 & 1 \\
\hline DumCap4 & $\begin{array}{l}\text { More than } 12 \text { trips a } \\
\text { year }\end{array}$ & Dummy & 0.29 & 0.45 & 0 & 1 \\
\hline Dum1 & Fishing ground grid 1 & Dummy & 0.02 & 0.15 & 0 & 1 \\
\hline Dum2 & Fishing ground grid 2 & Dummy & 0.06 & 0.24 & 0 & 1 \\
\hline Dum6 & Fishing ground grid 6 & Dummy & 0.09 & 0.29 & 0 & 1 \\
\hline Dum8 & Fishing ground grid 8 & Dummy & 0.02 & 0.16 & 0 & 1 \\
\hline Dum4B & Fishing ground Grid 4B & Dummy & 0.80 & 0.40 & 0 & 1 \\
\hline DumFG1 & Hand line and Troll Line & Dummy & 0.18 & 0.38 & 0 & 1 \\
\hline DumFG2 & Pole and line & Dummy & 0.01 & 0.10 & 0 & 1 \\
\hline DumFG3 & Purse seine & Dummy & 0.81 & 0.39 & 0 & 1 \\
\hline DSoff & $\begin{array}{l}\text { Off season period (Oct, } \\
\text { Nov, Dec, Jan, Feb) }\end{array}$ & Dummy & 0.43 & 0.49 & 0 & 1 \\
\hline DSpeak & $\begin{array}{l}\text { Peak season period } \\
\text { (March, April, May) }\end{array}$ & Dummy & 0.33 & 0.47 & 0 & 1 \\
\hline DStrans & $\begin{array}{l}\text { Transition period (June, } \\
\text { July, Aug, Sep) }\end{array}$ & Dummy & 0.24 & 0.43 & 0 & 1 \\
\hline
\end{tabular}


There are four dummy variables indicating how many fishing trips each captain made during the year 2015. DumCap1 takes a value of 1 if the captain made less than 2 trips a year, and zero otherwise. DumCap2 takes a value of 1 if the captain made 2-6 trips a year, and zero otherwise. DumCap3 takes a value of 1 if the captain made 6-12 trips a year, and zero otherwise. DumCap4 takes a value of 1 if the captain made more than 12 trips a year, and zero otherwise. As shown in Table 1, the average values of the four captain dummy variables were in the $0.19-0.29$ range, indicating that each captain category contained $19-29 \%$ of all observations. The captain dummy variables are used as a proxy variable for experience.

In all, it was possible to identify 29 different fishing grounds where the vessels fished in 2015. The identification was done on the basis of $1 \times 1$ degree grids, but finer grids of $0.5 \times 0.5$ degrees were also used. Most of the fishing, or over $80 \%$, took place in a single grid, which is represented by the dummy variable Dum4B.

Three dummy variables were defined for the fishing gear used in the Kendari tuna fishery; DumFG1 takes a value of unity if the vessel used hand line and troll line, and zero otherwise. DumFG2 takes a value of unity if the vessel used pole and line, and zero otherwise. DumFG3 takes a value of unity if the vessel employed purse seine, and zero otherwise. Just over $80 \%$ of the vessels in the sample used purse seine.

Three variables were also used to indicate whether the vessels were operating during the peak season or off season, or during a transition period. DSoff takes a value of unity if the fishing trip was made during the off season (October-February), and zero otherwise. DSpeak takes a value of unity if the trip was made during the peak season (March-May), and zero otherwise. DStrans takes a value of unity if the trip was made during the transition period (JuneSeptember)

\section{RESULTS AND DISCUSSION Results}

The results from estimating the model are presented in Table 2. As all variables are in logarithmic form, the parameter estimates can be interpreted as elasticities which show by how many percentages catches will increase if the use of each input is increased by $1 \%$. All the parameters in the model are statistically significant at the $1 \%$ level or better, with the exception of the parameter relating to the variable days at sea (DAS). This parameter takes a negative value, indicating that lengthening the fishing trip will lead to reduced catches. The increased utilisation of FADs can lead to vessels spending more time sailing between platforms in search of suitable fish aggregations, thus reducing the time actually spent for fishing. The negative value of the DAS-parameter appears to be picking up this effect. All the other variables have a significant positive impact on catches.

All the dummy variables in the inefficiency equation have a negative effect on inefficiency - and thus increase the efficiency of the vessels - as can be seen from the fact that all the estimated parameters in the inefficiency equation take a negative value. However, three of the parameters are not statistically significant from zero, those related to DumCap2, DumCap4 and Dum4B. The DumCap2 and DumCap4 variables refer to instances where the captain of the vessel went 2-6 fishing trips or more than 12 fishing trips in 2015. In order to avoid multicollinearity, dummy variable pertaining to cases where the captain went fewer than 1 or 2 trips per year (DumCap1) was not included in the regression model. The results therefore indicate that the efficiency of vessels with such captains was no different from the efficiency of captains who went 1 or 2 fishing trips in that year. However, having captains that went 6-12 trips a year has a positive effect on efficiency.

The choice of fishing grounds does not appear to matter much for efficiency, but vessels equipped with purse seine are more efficient. Efficiency is also higher both in the off-peak season and the peak season, than in the transitory period.

In Table 3, estimated technical efficiency is calculated across fleet segments. Technical efficiency is highest for purse seiners or 0.58 on average, but significantly lower for both pole and line vessels and vessels using hand and troll line. The least efficient vessels have a similar efficiency score for all three fleet segments, but the most efficient purse seiners and vessels using hand and troll line are much more efficient than vessels using pole and line. 
Table 2. Estimation results, output elasticities, and technical inefficiencies

\begin{tabular}{|c|c|c|c|c|c|c|}
\hline Item & Estimate & Std. & Error & & z-value & $\operatorname{Pr}(>|z|)$ \\
\hline \multicolumn{7}{|c|}{ Stochastic frontier model } \\
\hline (Intercept) & 6.0487 & 0.2109 & 28.6785 & & $<2.20 \mathrm{E}-16$ & 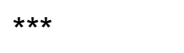 \\
\hline $\log ($ Crew $)$ & 0.2349 & 0.0411 & 5.7179 & & 1.08E-08 & *** \\
\hline $\log (\operatorname{Dim})$ & 0.0685 & 0.0140 & 4.9060 & & $9.30 \mathrm{E}-07$ & *** \\
\hline $\log (\mathrm{DAS})$ & -0.0804 & 0.0373 & -2.1558 & & 0.0311 & * \\
\hline $\log ($ Ice $)$ & 0.4275 & 0.0297 & 14.4009 & & $<2.20 \mathrm{E}-16$ & *** \\
\hline $\log ($ Water) & 0.2001 & 0.0194 & 10.2966 & & $<2.20 \mathrm{E}-16$ & $* * *$ \\
\hline \multicolumn{7}{|c|}{ Ineffieciency fator } \\
\hline (Intercept) & 1.2583 & 0.1284 & 9.7983 & & $<2.20 \mathrm{E}-16$ & *** \\
\hline DumCap2 & -0.0810 & 0.0788 & -1.0284 & & 0.30374 & \\
\hline DumCap3 & -0.2005 & 0.0949 & -2.1132 & & 0.03458 & * \\
\hline DumCap4 & -0.0254 & 0.0916 & -0.2768 & & 0.78192 & \\
\hline Dum4B & -0.0240 & 0.0688 & -0.3485 & & 0.72748 & \\
\hline DumFG3 & -0.4924 & 0.0875 & -5.6263 & & $1.84 \mathrm{E}-08$ & $\star \star \star ~$ \\
\hline DSoff & -0.2693 & 0.0622 & -4.3315 & & $1.48 \mathrm{E}-05$ & $\star * *$ \\
\hline DSpeak & -0.4152 & 0.0896 & -4.6361 & & 3.55E-06 & *** \\
\hline sigmaSq & 0.4473 & 0.0534 & 8.3776 & $<$ & $2.20 \mathrm{E}-16$ & *** \\
\hline Gamma & 0.7070 & 0.0247 & 28.6620 & $<$ & $2.20 \mathrm{E}-16$ & $* * *$ \\
\hline
\end{tabular}

Significance codes: $0\left(^{* * *}\right), 0.001\left(^{* *}\right), 0.01\left(^{*}\right), 0.05(),. 0.1(), 1$

Table 3. Summary statistic of the efficiency

\begin{tabular}{lcccc}
\hline Parameter & All & Purse seine & Pole and line & Hand and troll line \\
\hline $\mathrm{N}$ & 2598 & 2107 & 26 & 466 \\
Average & 0.5431 & 0.5764 & 0.3707 & 0.4018 \\
Min & 0.0934 & 0.0989 & 0.0994 & 0.0934 \\
Max & 0.9061 & 0.9061 & 0.7165 & 0.8718 \\
Stdev & 0.1737 & 0.1653 & 0.1378 & 0.1308 \\
\hline
\end{tabular}

Efficiency distribution of the tuna fishing fleet in Kendari is skewed to the right evident from Figure 1 which shows that the estimated technical efficiency of $40 \%$ of the vessels is below the average. The estimated efficiency of $20 \%$ of the vessels is in the $0.7-0.8$ range while the efficiency of more than $21 \%$ of the fleets is estimated as greater than 0.8 .

In Figure 2 and Table 4, the seasonality of the estimated technical efficiency is analysed in more detail. The dark black line in Figure 2 represents the estimated technical efficiency of vessels active during the peak season (March-May) while the grey line represents the efficiency of vessels during the off season (October-February). The dotted line shows estimated efficiency of vessels in the transitory season (June-September). Estimated efficiency is highest during the peak season, but overall there is not a great difference between the technical efficiency of vessels operating during the peak season and off season. The frequency distribution during three different period also shows different patterns, with the distribution of the peak season more skewed to the right than the distribution of the other season. 


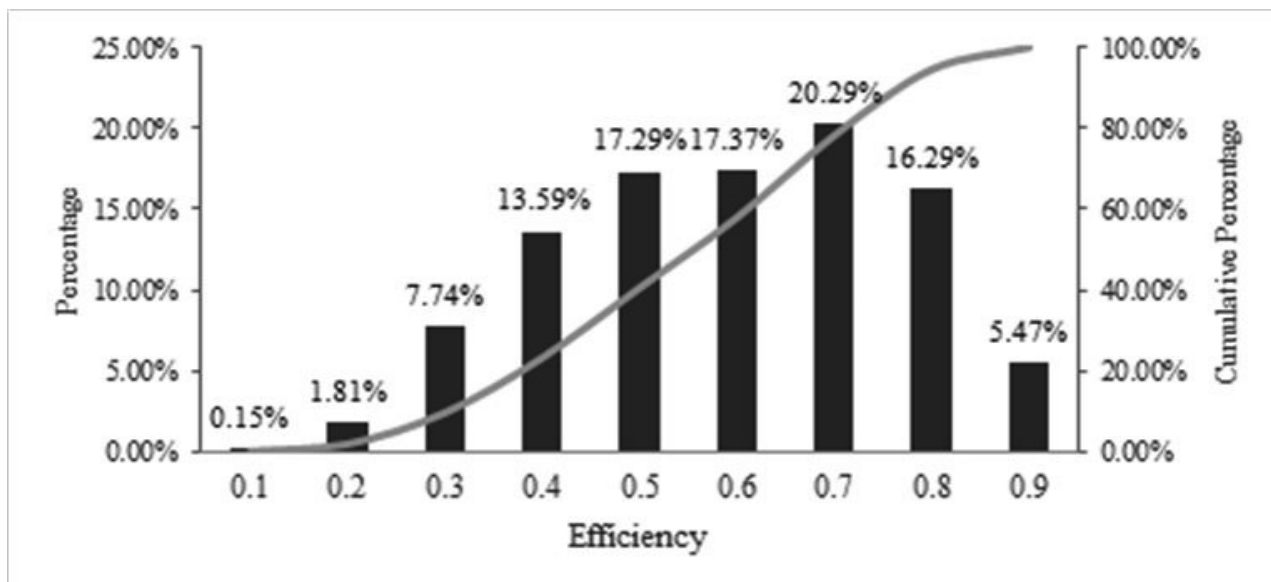

Figure 1. Frequency distribution of the estimated technical efficiency.

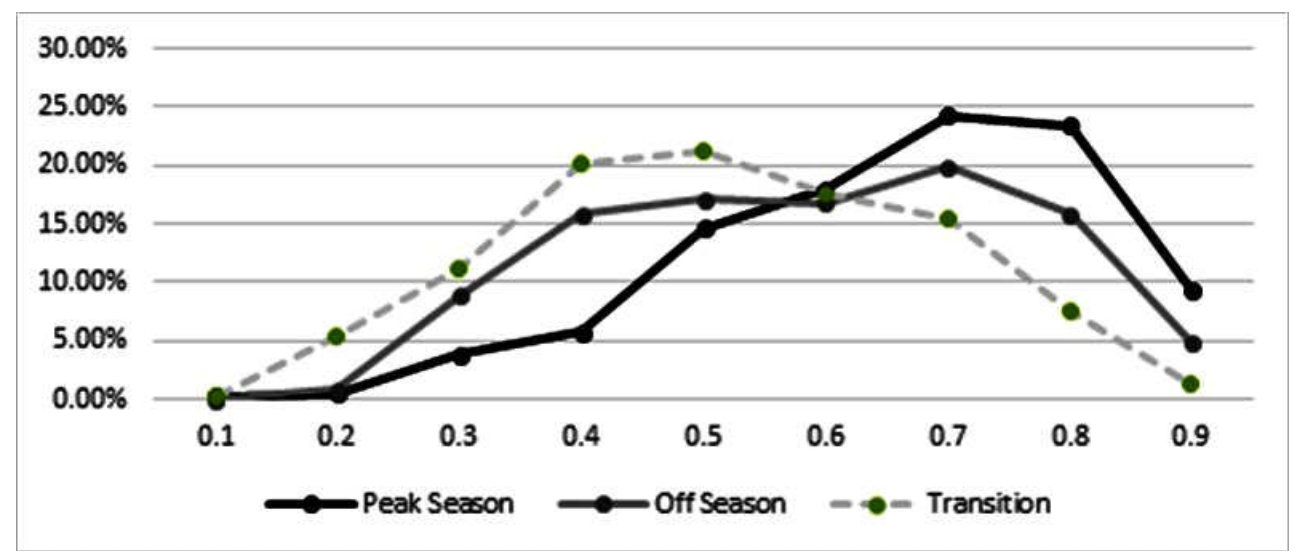

Figure 2. Efficiency frequency distribution for different seasons.

From Table 4 tabulation it is clear that average efficiency is highest during the peak season and the standard deviation lower. However, the difference between the peak and off seasons is not large only between

Table 4. Efficiency distribution and summary for 3 different season

\begin{tabular}{lcccrrr}
\hline Efficiency & \multicolumn{2}{c}{ Peak Season } & \multicolumn{3}{c}{ Off Season } & \multicolumn{2}{c}{ Transition } \\
\hline$[0.0,0.1)$ & 3 & $0.35 \%$ & 0 & $0 \%$ & 2 & $0 \%$ \\
{$[0.1,0.2)$} & 5 & $0.58 \%$ & 9 & $1 \%$ & 34 & $5 \%$ \\
{$[0.2,0.3)$} & 33 & $3.85 \%$ & 98 & $9 \%$ & 70 & $11 \%$ \\
{$[0.3,0.4)$} & 49 & $5.71 \%$ & 176 & $16 \%$ & 128 & $20 \%$ \\
{$[0.4,0.5)$} & 125 & $14.57 \%$ & 190 & $17 \%$ & 134 & $21 \%$ \\
{$[0.5,0.6)$} & 154 & $17.95 \%$ & 186 & $17 \%$ & 111 & $18 \%$ \\
{$[0.6,0.7)$} & 209 & $24.36 \%$ & 221 & $20 \%$ & 98 & $16 \%$ \\
{$[0.7,0.8)$} & 200 & $23.31 \%$ & 176 & $16 \%$ & 47 & $7 \%$ \\
{$[0.8,0.9)$} & 80 & $9.32 \%$ & 54 & $5 \%$ & 8 & $1 \%$ \\
Average & 0.6068 & & 0.5383 & & 0.4652 & \\
Min & 0.0989 & & 0.1020 & & 0.0934 & 0.8723 \\
Max & 0.9061 & & 0.8733 & & 0.1667 & \\
Stdev & 0.1562 & & 0.1715 & & & \\
\hline
\end{tabular}


Results from estimating the stochastic production frontier indicated that the length of the trip as measured by days at sea had a negative effect to the catch, longer the operation days was associated with lower catch, but statistically insignificant effect on catches. In Figure 3 the relationship between trip length and estimated efficiency is analysed in more detail. The Figure clearly reveals that vessels that spend many days at sea tend to have rather lower efficiency. Indeed, most of the points corresponding to those long trips lie below the average level.

Figure 4 indicates, there is a non-linear relationship between numbers of crew and estimated efficiency. Technical efficiency is low for vessels with small and large crews, but larger for vessels with crews of 10-20 individuals.

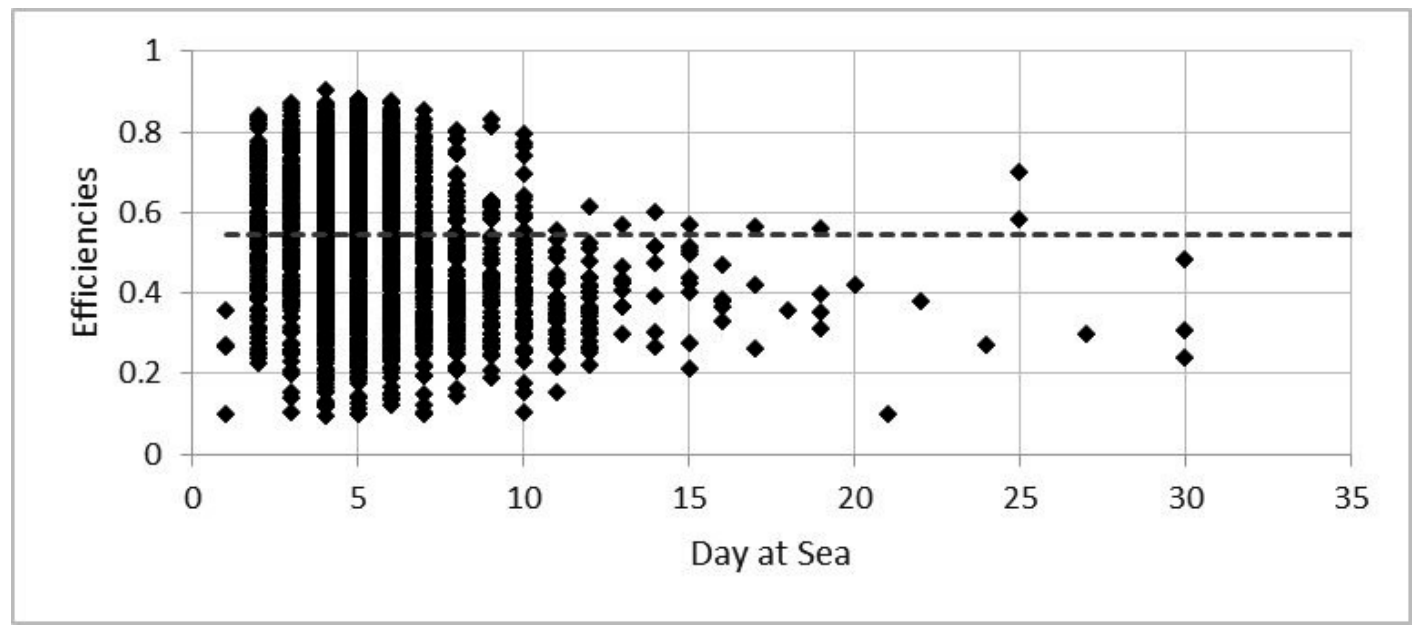

Figure 3. Technical efficiency according to length of fishing trip.

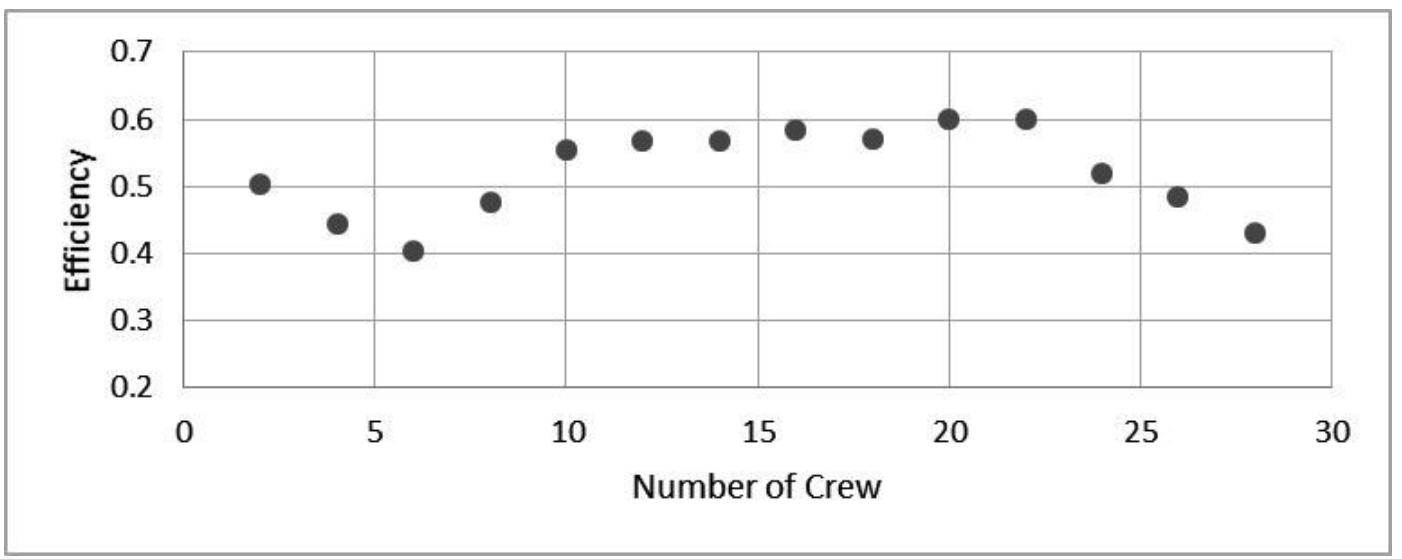

Figure 4. Average technical efficiency according to the size of vessel crew.

Available data from the analysis also allows for comparison of technical efficiency of the same vessels between individual fishing trips as it is shown in Figure 5 where the spread of estimated technical efficiency of the tuna vessels according to the number of trips undertaken by each vessel. Vessels with fewer than 12 trips a year were excluded from this comparison. Seven vessels identified have being very efficient. The efficiency of these vessels was estimated much higher than the average and the spread of estimated efficiency as measured by the difference between maximum and minimum efficiency scores was quite narrow. As these vessels were not always captained by the same individual, the efficiency of the vessels must first and foremost be related to the vessel specification and use of inputs. Other vessels always perform poorly; the estimated efficiency is low and the variations of efficiency scores high. These vessels might need more talented captains or try to operate more often during the peak fishing season and fish were catches can be expected to be better. 


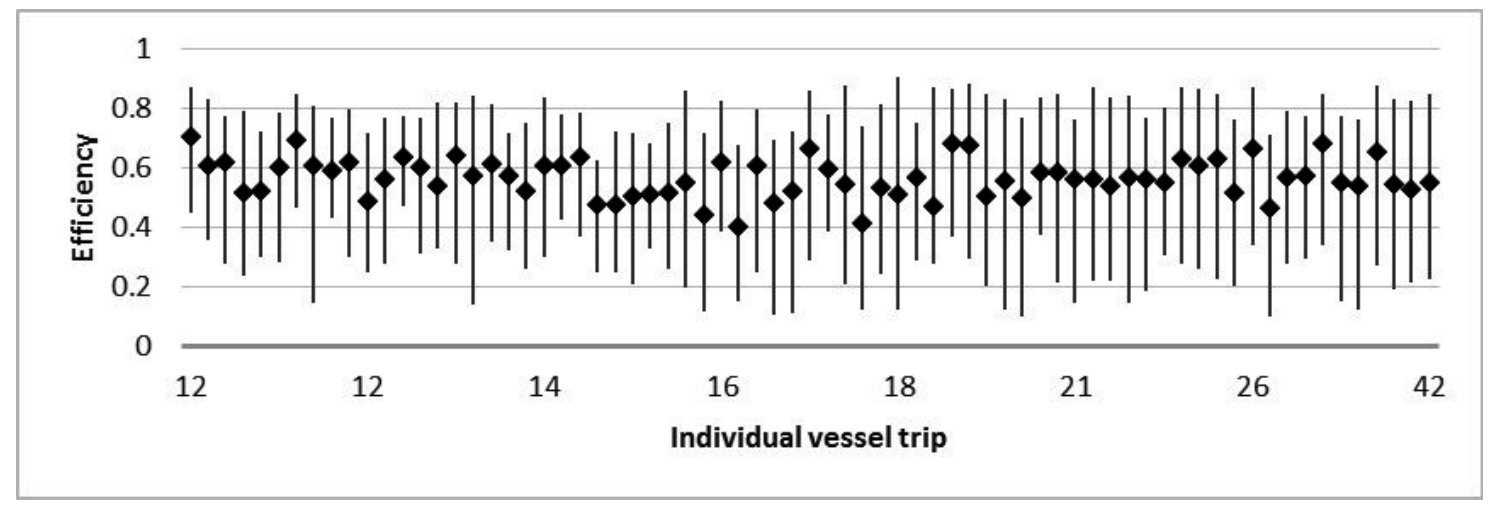

Figure 5 Spread of technical efficiency of individual fishing vessels.

\section{Discussions}

Result of technical efficiency analysis shows that the mean efficiency score is 0.5485 , this show that the ability of the FAD associated tuna fishery in Kendari to convert the input variable into output (catch) is still lower. The level of , this technical efficiency is lower than the study done by Jeon et al. (2006) for the purse seine fishery in Java Sea Indonesia (mean value 0.61 ).

This lower value of technical efficiency could indicate two phenomena, first interpretation for this lower technical efficiency (TE) value is it could be the sign of the decreasing of the FAD ability to support the fishing operation due to the extensive increasing number of FAD. Extensive investment in deploying the FAD has led to decreasing of the FAD effectiveness to aggregate the fish and support the fishing operation to generate catches. We could see this phenomenon from negative relationship between TE and number days at sea (DAS). Second interpretation of this lower TE value is probably due to crews or captain lower skills and capacity as well as the vessel ability, to convert all the effort factors into catch during the fishing operation. There are also possibility of both explanation could be combine and contribute to the lower value of TE.

Seasonality also contributed to the efficiency level in FAD associated tuna fishing fleet in Kendari. Seasonality effect to the TE value has slightly differences with the results obtained by Jeon et al. (2006) who used different dummies for the different fishing season to see the effect of the seasonality on technical efficiency. Their study revealed that efficiency is highest during peak season than in the off season, the differences between the peak season and the off season was significant. In this study the $T E$ value differences between the peak season and the off season was not significant, this indicated that the FAD fishery in Kendari was only slightly influence by the seasonality.
Comparing to other study done by Nugraha \& Hufiadi 2013 for the Longline fishing fleet using the DEA (data envelopement analysis), this study offer new method and perspective since this study utililized stochastic process on the catch and input data technical efficiency model developmnet. This study will be much more powerfull if we input time series data panel so we could detect the technical efficiency changes over time on the FAD fishery in Kendari.

\section{CONCLUSION}

The increasing number of FAD tends to have impact on the technical efficiency, mean efficiency still on the low - medium level on 0.534 , and if we see in more detail day at sea shows negative impact on the catch, this is one indication that the number of days at sea has been increased affect by the increasing in number of empty FAD. This over investment lead to inefficiency operation and the FAD function as the aggregating devices become less efficient. I need to increase crew and captain skill and capacity to increase the efficiency so the productivity (catch). Also the quality of the catch will be increasing, this could be done through training and also workshop in related field of study (Post Harvest losses reduction, better fishing skills etc.)

\section{AKNOWLEDGEMENT}

I would like to thank also "Developing Research Capacity for Management of Indonesia's Pelagic Fisheries Resources Project" a collaboration project between Research Centre for Fisheries Management and Conservation (RCFMC) - MMAF Indonesia and Australian Centre for International Agricultural Research (ACIAR). Head of Kendari Fishing port for the permit to conduct the study, and also the all Kendari fishing port staff for the very helpful assistances during data collection. 


\section{REFERENCES}

Aigner, D. J., Lovell, C. \& Schmidt, P. (1977). Formulation and estimation of stochastic frontier production function model. Journal of Economometrics, 6, 21-37.

Battese, G. E. \& Coelli, T. (1995). A model for technical inefficiency effect in a stochastic frontier production function for panel data. Empirical Economics, 20, 325-332.

Coelli, T. \& Henningsen, A. (2013). frontier: Stochastic Frontier Analysis. R package version 1.1-1. http:/ /CRAN.R-Project.org/package=frontier.

Coglan, L., Pascoe, S. \& Harris, R. (1999). Measuring efficiency in demersal trawlers using a frontier production function approach, In: Salz, P. (Ed), Proceedings of the Xth Annual Conference of the European Association of Fisheries Economics, The Hague, 1998. The Hague: Agricultural Economics Research Institute (LEI-DLO), 236-257.

Croissant, Y. \& Millo, G. (2008). Panel data econometrics in R: The plm Package. Journal of Statistical Software, 27(2). Retrieved from http:// www.jstatsoft.org/v27/i02/.

Directorate General of Capture Fisheries. (2013). Capture fisheries statistic of Indonesia, 2013. Ministry of Marine Affair and Fisheries. Jakarta: Directorate General of Capture Fisheries.

Fousekis, P. \& Klonaris, S. (2003). Technical efficiency determinants for fisheries: a study of trammel netters in Greece. Fisheries Research, 63, 85-95.

Ghee-thean, L., Latief, I. A. \& Hussein, M. A. (2012). Does technology and other determinat effect fishing efficiency? an application of stochastic frontier and data envelopment analyses on trawl fishery. Journal of Applied Sciences, 12(1), 48-55.
Jeon, Y., Omar, I. H., Kuperan, K., D., S. \& Susilowati, I. (2006). Developing country fisheries and Technical efficieny: the java Sea purse seine fishery. Applied Economics, 38, 1541-1552.

Kirkley, J.E., Squires, D.E. \& Strand, I.E. (1995). Assessing technical efficiency in commercial fisheries: The Mid-Atlantic Sea Scallop Fishery. Am. J. Agric. Econ., 77(3), 686-97.

Kirkley, J.E., Squires, D.E. \& Strand, I.E. (1998). Characterizing managerial skill and technical efficiency in a fishery. J. Product. Anal., 9, 145160.

Meeusen, W. \& van den Broeck, J. (1977). Efficiency estimation from Cobb-Douglas production function with composed error. International Economic Review, 18, 435-444.

Nugraha, B. \& Hufiadi. (2013). (In Indonesian) Technical efficiency of tuna longline fisheries in benoa (case study of PT. Perikanan nusantara). J.Lit.Perik.Ind. 19 (1), 25-30

Pascoe, S., Andersen, J.L. \& de Wilde, J.W. (2001). The impact of management regulation on the technical efficiency of vessels in the Dutch beam trawl fishery. Europ. Rev. Agric. Econ, 28(2), 187206.

Pascoe, S. \& Coglan, L. (2000). Implications of differences in technical efficiency of fishing boats for capacity measurement and reduction. Mar. Pol., 24(4), 301-307.

Sharma, K.R. \& Leung, P. (1999). Technical efficiency of the longline fishery in Hawaii: an application of a stochastic production frontier. Mar. Resource Econ, 13, 259-274.

Squires, D.E. \& Kirkley, J.E. (1999). Skipper skill and panel data in fishing industries. Can. J. Fish. Aquatic Sci, 56, 2011-2018. 